\title{
Establishing Geriatric Services: The Success Story of Ain Shams University -Egypt
}

Doha Rasheedy ${ }^{1,2}$, Rania Mohammed Abou-Hashem ${ }^{1,2}$, Ahmed Shawky Mohammedin ${ }^{1,2}$, Hany Ibrahim Hassanin ${ }^{1,2}$, Heba Mohamed Tawfik

1 Geriatrics and Gerontology Department, Ain Shams University, Egypt.

2 Member of ECARE: the Egyptian Cognitive and Ageing Research scientific interest group.

\section{Outline:}

1. Introduction

2. The need for geriatric care models

3. The historical background of geriatric medical services in Ain Shams University

4. The Medical services:
a. The team
b. Geriatric day Care
c. Geriatric outpatient clinics
i. Geriatric outpatient clinics
ii. Health promotion clinic
iii. Memory clinic
iv. Falls and osteoporosis clinic
v. Acute Geriatric Care (Geriatrics inpatients ward):
vi. Geriatrics critical care unit
vii. Geriatrics Intermediate care unit
viii. Orthogeriatric care model
ix. Home care
d. Funding Resources for medical services
e. Number of patients

5. Cutting-Edge Technology and innovative projects at Ain Shams University Geriatric hospital

6. Training needed to ensure competence in the new model

7. Research in Geriatric medicine

8. Ways to go

9. Strategic approaches

10. Appendix 1: Milestones and events of Geriatric medical service establishment in Egypt

\section{Introduction}

The Ain Shams geriatric medicine services experience can be considered as a state-of-the- art healthcare service in Egypt. The service has undergone several changes and development over the past 39 years since its start in 1980. Now it has developed as the standalone Engineer Ahmed Shawky geriatrics hospital as part of the Ain Shams university hospitals.

It is difficult to point out the perfect strategy to establish a geriatric medicine service. Probably no one knows all answers or the best answers on how to build a service smoothly. We are going to review briefly how the service has developed.

The late Professor Abdel-Moniem Ashour was the major contributor to the establishment of geriatric medicine services in Ain Shams University. He has once described it as "trying to make a nice painting 
from several mosaic pieces". Together with the late Professors Mohammed Sabbur and Essam Fekry, the three of them led the introduction of geriatric medicine to Egypt.

It is difficult to get all data related to establishment of a service that has started 39 years ago. This review has been formulated after reviewing Ashour and Sabour writings. Both were the leading co-founders of Ain Shams geriatric medicine unit in different sources. We have tried to make a chronological summery of the main events and methods as documented in published articles, books, documents, reports, commentaries, and personal communication stories. Indeed, Ain Shams geriatrics healthcare service must be viewed in the context of the development of Geriatric medicine services in Egypt.

The introduction and establishment of any elderly care service is a huge challenge. It is usually associated with a mix of success and failure stories. These efforts need real Heroes. Heroes that understand that they are going to sacrifice effort, time and resources to make their dream come true. Probably they are not going to be remembered or thanked for all their efforts. However, "success/victory has a thousand father, but failure/defeat is an orphan".

It all started with the sense of personal duty to do all efforts to help relief elderly suffering in the healthcare services and help its transformation to "align health systems to the needs of older people" as one of the WHO 10 Priorities for a Decade of Action on Healthy Ageing. ${ }^{2}$ Success is no accident. It is hard work, perseverance, learning, studying, sacrifice and most of all, love of what you are doing or learning to do. ${ }^{3}$

Until today, "The major barrier to the health of elderly may lie less in their own bodies than in the minds of their physicians and others in the community in large". ${ }^{4}$ That is why the WHO is pushing to "Undertake a global campaign to combat ageism" as one of the WHO 10 Priorities for a Decade of Action on Healthy Ageing. ${ }^{2}$ Also, the WHO's World report on Ageing and Health has addressed Ageism within health care as a major challenge to active and healthy ageing. ${ }^{5}$ Perhaps Geriatricizing ${ }^{6}$ of the healthcare service is the most important contribution of a Geriatric medicine service.

\section{The need for geriatric care models:}

There is greying of nations with increase in life expectancy of population all over the world due to enhanced public health services i.e. better water supply, better sewage, better housing then vaccination with decreased mortality. The aged population nowadays is at its highest level in human history, thus the needs of the elder should be the focus of our attention.
The number of elderly people has tripled since 1950, and the number of geriatric population will reach 2.1 billion by $2050 .{ }^{7}$ In Egypt, the percent of elderly population in 2018 between 55 and 64, and 65 and above years of age was $5.95 \%$ and $4.22 \%$; respectively.

\subsection{Elderly are different: $:^{8-10}$}

$>$ They are heterogeneous group of population (active ager, prefrail/ vulnerable, and frail) ${ }^{11}$ requiring multiple levels of care (e.g. acute healthcare setting, long-term care, assisted living facility, day care, skilled nursing facility, home care)

$>$ Evaluation of an elderly patient usually takes longer and requires more diagnostic tests due to unusual presentations of illness; e.g., an elderly patient suffering from pneumonia can present with delirium or falls.

$>$ The altered pharmacokinetics and pharmacodynamics with aging needs better understanding of the interactions and adverse effects of drugs.

$>$ The need to manage multiple comorbidities for better outcomes and to avoid side effects of drugs, drug interactions and hazards of polypharmacy. However, current evidencebased medicine is built on mono-morbidity and excluding elder patients from clinical trials; creating many knowledge gaps while managing elderly in routine clinical practice. ${ }^{12}$

$>$ Attribution of diseases to age related changes; hence the differentiation between age related changes and diseases is of utmost importance through obtaining good knowledge about age related physiological changes in various body systems.

$>$ Some geriatric giants are commonly presented in those people late in life like Alzheimer's disease, Parkinson's disease, osteoporosis and urinary incontinence, and frailty which is not confined to elderly, but occurs in younger risky groups e.g. down syndrome, degenerative neuromuscular diseases, and cerebral palsy.

$>$ Elderly are liable to malnutrition and need good nutritional assessment and management in collaboration with Multidisciplinary team (MDT).

$>$ Functional decline is very common in acute illness. Therefore, one of our important targets in geriatric medicine is to restore the patient's function and to improve the patient's quality of life, this requires MDT including the geriatrician/ geriatricized physician, a qualified geriatric nurse/geriatricized nurse, and physical, social and occupational (for environmental modification) therapist 
$>$ Retirement along with other multiple transitions, and multiple losses mandate paying enough attention to social, financial, and psychological assessment and support.

\section{The historical background of geriatric medical services in Ain Shams University: ${ }^{13,14}$}

It all started with the dream of four great men: Professor Abdel-Moneim Ashour, Professor Abdo Sallam, Professor Mohammed Essam Fekry, and Professor Mohammed Sabbur who founded the Egyptian Geriatric Society in 1982. Those pioneers were responsible for raising the awareness regarding the special needs of elderly patients and building the professional capacity to deal with the upcoming growing challenge of dealing with elders' needs since mid-1970s.

The first geriatric unit was established in Alexandria University in 1980. Later, Ain Shams University founded its own geriatric unit in 1982 providing the medical counseling to elderly through the day care service.

In 1984, an outpatient geriatric clinic was formally initiated. The inpatient ward and the academic unit were established in 1996. Professor Moatasem Salah Amer, Professor Mohammed al-Banouby, and Professor Ahmed Kamel Mortagy joined the department. Their specialties were internal medicine, Neurology, and public health, respectively. Four residents were recruited from the neurology department.

In the following years, four geriatric residents were appointed each year. Later the number of residents has increased to 8 residents yearly.

\section{Early International collaborations:}

- Partnership between the University of Minnesota and Ain Shams University Bilateral Research on Training in Geriatrics Funded by the Fulbright Commission was initiated in 1992. (the Fulbright Bi-National Commission Partnership Project with Ain Shams University, Minneapolis, $\mathrm{MN}$ and Cairo, Egypt). ${ }^{15}$

- Partnership with United Nation's International Institute of Aging (INIA) in Malta to carry out short-term training programmes in Cairo.

- Visiting Professorships

Kenneth Hepburn January 1995 \& February 1998

Richerd Reed

James Pacala

Peter Millard

Laura Efinger Occupational Therapist 2010
Geriatric ICU was established in 2002, the geriatric residents underwent 6 months of intensive care training in the medical critical care unit in Ain Shams University hospital.

Many medical, academic, and scientific services were established during the development of our geriatric model in Egypt until the establishment of the standalone Engineer Ahmed Shawky geriatrics hospital as part of the Ain Shams university hospitals (the first geriatric hospital in Egypt and Arab world).

\section{The Medical services:}

Our department provides state of the art healthcare services for older people (active, prefrail, or frail) in the outpatient clinics, and hospital setting.

\subsection{The multidisciplinary team (MDT): ${ }^{16}$}

The composition of MDT is determined according to the healthcare needs of the patient population and the available resources. It typically consists of a core team consisting of a geriatrician/ geriatricized physician, a qualified geriatric nurse/geriatricized nurse, and social worker. According to the patient's needs the team can be supplemented by other disciplines e.g. physical and occupational therapists, clinical nutritionists, clinical pharmacists, and psychologists (extended team model).

However, when we established our service back in 1980, we lacked the trained but more importantly the motivated geriatricized personnel. The ASU geriatric department was launched under supervision of 4 professors (psychiatry, neurology, internal medicine, and public health). Soon 4 neuropsychiatric residents joined the team.

Other team members included:

- Head nurse, staff nurses, and nursing aids

- Psychologist

- Speech therapist

- Clinical Dietitian

- Social worker

This team is responsible for multidimensional assessment of the patients' needs (physical, psychological, and social) and designing an individualized care plan based on each patient's needs, goals and capabilities.

Our geriatric model is composed of the Geriatric day care (now closed), Geriatric outpatient clinics, Geriatric inpatient ward, and Geriatric ICU 


\subsection{Geriatric day Care:}

It was the first service provided by our department. It included health check-up, hot meal, recreation, medication review, exercises to the attendants. However, the service was ended in 1990 when the formal clinic and in-patient ward were established, Ministry of Social Solidarity now provides similar service in many elderly clubs throughout the country.

Our department contributes to daycare services in collaboration with many NGOs e.g. Alzheimer's Egyptian day care meetings and the mobile geriatrics hospitals in social clubs and elderly clubs.

\subsection{Geriatric outpatient clinics:}

The Geriatric Outpatient Clinics started with one clinic that was located in Ain Shams university hospital. It offered a consultative assessment provided by a geriatrician and the MDT members.

Recently in January 2019, specialized geriatric clinics (Geriatric Problem-Focused Clinic) were launched. They included memory clinic, osteoporosis and fall assessment clinic, and health promotion clinic. They provide unique services to cover special needs of elderly people with highly specialized practitioners to help them maintaining independency in their community. However, the incontinence and Geriatric clinical nutrition clinics are being planned.

\subsubsection{Geriatric medical clinic (on daily basis)}

- Eligible patients (the patients that are likely to benefit from geriatric medical service)

1. Elderly patients aged 60 years and more with multiple complex acute and chronic medical co-morbidities associated with aging such as poor appetite, unexplained weight loss, bowel or bladder problems, malnutrition ......., with special attention for promoting functional state and improving quality of life of elderly and their caregivers.

2. Elderly with one or more geriatric syndrome. for example,

- Dementia syndrome

- Delirium syndrome

- Frailty syndrome

- Functional decline

- Urinary incontinence

- Polypharmacy

- Elder abuse

- Unsteady gait/falls

- Malnutrition

- Late life Depression

3. Follow up the patients after discharge from the acute geriatrics care through follow up appointments.

4. Those with complicated medication plan (including history of adverse drug reactions).

5. Those reported unexplained decline in functional status and/or declined capacity for self-care, falls, or memory complaints.

Patients that are NOT likely to benefit from the Geriatric medicine service are allocated to other levels of care (Emergency department, Long term care, etc......)

- Services provided include:

1. Comprehensive Geriatric Assessment aiming to reduce inappropriate admissions and support continuous care in the community. It includes medical history, physical examination, cognitive, functional and mood evaluation with focusing on acute and uncontrolled medical condition.

2. Geriatric consultation a problem focused assessment of an inpatient or an outpatient by a physician with or without the additional input of a team.

3. Health promotion of the elderly; It targets elderly population (active, prefrail, and frail) having three basic goals: maintaining and enhancing functional capacity, maintaining or improving self-care, and enhancement of the patient's social network and maintaining quality of life.

4. Medication review and deprescribing unnecessary medications e.g. proton pump inhibitors, neuropsychological medications.

5. The team may recommend consultations with other specialties such as an endocrinologist, cardiologist, ophthalmologist, audiologist ...etc.

6. Social and financial assessment by social worker with appropriate referrals to needed governmental and non-governmental resources providing support for the patient and their caregivers.

- The medical conditions managed within the geriatric medical clinic include:

- Diabetes and its related complications

- Heart Diseases

- Subacute care of stroke/CVA

- Hypertension

- Hyperlipidemia

- Thyroid disorders

- COPD-BA-IPF

- $\quad \mathrm{AKI}, \mathrm{CKD}$, Anemia in elderly

- Gastritis, dyspepsia, and Irritable 
bowel disease

- Gastroesophageal Reflux Disease

- Common Infections such as common cold, acute bronchitis, pneumonia and UTI.

- Assessment and management of weight loss, diarrhea and constipation.

\subsubsection{Health promotion clinic (twice weekly):}

This clinic aims early detection and management of chronic conditions to prevent complications, functional decline and mortality. It provides service for elderly patients aged 60 years and older with or without stable co-morbid conditions but not those with acute medical conditions. It provides expanded scope of services including:

- Early detection of common asymptomatic diseases (DM-HTN-hyperlipidemia- thyroid illness, etc.......)

- Functional assessment.

- Psychological assessment for early detection of depression and anxiety.

- Cognitive assessment for early detection of mild cognitive impairment and dementia.

- Pain assessment and treatment.

- Screening for elderly patients with increased risk of falls.

- Screening for sleep problems.

- Screening for sensory deprivation.

- Nutritional assessment for malnutrition.

- Providing elderly patients with a schedule for recommended vaccinations

- Health education measures regarding smoking cessation, healthy diet and regular exercise.

- Caregiver education and counseling.

- Screening for elderly abuse and caregiver burnout.

- Any required laboratory and radiological investigations at reduced prices.

- Referral to other specialties.

However, this service is hampered by the lack of community awareness regarding the importance of disease screening (most of the elderly patients seek medical advice only with an urging complaint.

\subsubsection{Memory clinic (Twice weekly):}

Many older adults complain of memory problems or decline in other cognitive skills and sometimes they consider these problems as a part of normal ageing process. However, these cognitive complaints may be due to Alzheimer's disease or an underlying disease (DM-HTN-stroke-depression]. Thus, early assessment and timely management of memory problems may delay progression of the disease and related consequences.

The clinic provides services for older adults with memory loss, difficulties in thinking or concentration, behavioral changes, or dementia.

\section{Services provided:}

- Assessment, diagnosis, and management of cognitive problems and associated behavioral disturbances through full history, medical examination, neuro-cognitive tests, functional assessment and investigations.

- Development and implementation of a management plan that includes pharmacological, non-pharmacological approaches, cognitive training/ rehabilitation or psychotherapy.

- Allocating patients and caregivers to appropriate community resources.

- Education and support of the caregivers regarding how to deal with demented patient.

\subsubsection{Falls and osteoporosis clinic (Twice weekly):}

Falls is considered one of the major geriatric syndromes; as it increases morbidity, mortality, and dependence. Sometimes the patient or his family consider falls as part of aging or they are confused regarding which specialty can manage this problem or what are the complications of this problem.

Many falls related complications such as injuries or fractures are managed by other specialties, but the cause of falls may not be assessed nor managed.

The falls and osteoporosis clinic provides proper assessment and management for different causes of falls and consequently decreasing its complications and risk of recurrence.

We recruit elderly patients who have experienced a fall or a fall related complication such as injuries or fractures and those at risk of falling or have a fear of falling, those with osteoporosis. We also provide preoperative assessment of elderly patients with new fractures who are at risk for post-operative complications such as delirium.

One of the major limitations for this service is the lack of In Site physiotherapist and occupational therapist. 


\subsection{Acute Geriatric Care (Geriatrics inpatients ward):}

The global ageing is a health care challenge that hospitals cannot simply face through increasing the numbers of beds. The provided hospital care services should adapt to the heterogeneous and complex physiological, functional, psychological, and social needs of the elderly patients.

Hospitalization is a stressful event for older adults associated with multiple adverse outcomes including functional decline, delirium, undernutrition, polypharmacy, along with other well-known iatrogenic events. ${ }^{17}$ Elderly patients need specific care approaches during hospitalizations in order to prevent this cycle of adverse outcomes.

Acute geriatric care unit is a specialized form of a medicine ward that admit frail, aged inpatients risky for functional decline, hospitalization-associated deconditioning, delirium, and prolonged length of stay in the inpatient environment. ${ }^{18}$

The ACE units adopt an interdisciplinary team model as opposed to a multidisciplinary model. An interdisciplinary team model integrating knowledge and methods from different disciplines to collaboratively develop the patient-centered care plan. ${ }^{17}$

An ACE unit is safe and appropriate care facility for elder patients with acute medical problem. It allows for rapid multidimensional diagnostic process, rapid investigations and planned individualized interventions for the person's acute illness that promote independence to maintain optimal function and prevent polypharmacy, delirium, deconditioning, cognitive impairment and deconditioning.

\section{Eligible patients for Geriatric Ward admission: ${ }^{19}$} Age $>60$ years

1. Elderly with acute functional decline

2. Elderly with acute cognitive decline

3. Elderly with multiple medical, functional and/or psychosocial problems, who could benefit from an interdisciplinary team approachi

4. Elderly with acute medical problem in addition to one or more "geriatric syndrome(s)"

We exclude elderly that will not benefit from admission to inpatient department: Stable Elderly that need long term care e.g. Stable dementia.

The admission of older people may be directly from the community, through the Geriatric Consultation outpatient clinic or through referral from general wards or emergency department.

\section{The physical environment:}

Acute geriatric care units was designed to promote independence, for instance the use of color contrasting for low vision; using handrails in bathrooms, patient rooms, and hallways; the furniture was designed to ease transfers; clear signs for toilets, clinics....etc., prepared paths for wheelchairs.

Yet intention to create communal areas for dining and group activities, access to outdoor spaces toy help patients with cognitive impairment exists. Slippery or reflective floors were avoided.

The acute elderly care in Geriatric ward works closely with: 18

- Rehabilitation services

- Palliative Care

- Older Persons Mental Health Services

- Dental Services

- Ophthalmology Unit

- Audiological rehabilitation program

- Speech and swallowing therapy Unit

- community based services

- Residential Aged Care providers

Services provided through the acute geriatric care unit:

- CGA: A multidisciplinary multidimensional diagnostic process focused on determining patient's medical, psychological and functional capability to develop an integrated plan for treatment and long term follow up.

- Medication review: avoid unnecessary poly pharmacy, address the drug- drug, drugdisease and drug nutrient interactions.

- Assess the patient's ability to obtain and take drugs as prescribed and ability to attend the follow up visits.

- Assessment of caregiver capabilities and signs of burnout or signs of elderly abuse.

- Planning for care transition from the day of admission, however; the care transition in our facility requires more advancement. Currently, transition occurs through providing the patient a discharge summary including a brief report of the condition with the plan for treatment and follow-up.

- Family participation is promoted (the patients and their caregivers) through regular family 
meetings with the case manager

- Health care promotion: health education, vaccination program, screening for malignancy, and screening for subtle geriatric syndromes.

- The daily clinical rounds are done by the residents and twice a week by the consultants, some cases are presented at the weekly medical conference.

The acute geriatric care unit in Ain Shams University started as a small unit $(23$ Geriatrics ward beds and 8 ICU beds) under the administrative authority of the internal medicine department. In August 2018, Ahmed Shawky Hospital The first hospital for the elderly medicine was established with 66 Geriatrics ward beds and 24 ICU beds.

\subsection{Geriatrics critical care unit:}

The elderly population accounts for approximately onehalf of all patients admitted to the ICU. However, the mortality rate for elderly patients admitted to the ICU remains unacceptably high. Not all intensivists are aware of the specific needs of elderly patients, and their training still lacks a geriatric focus. ${ }^{20}$

Possibly the old and very old patients are subjected to discrimination based on age when admitted to intensive care units. They often do not receive adequate diagnostic work-up and treatment compared to younger patients. In patients with acute myocardial infarction, the elderly usually have delayed treatment and they are less likely to receive the recommended medical and

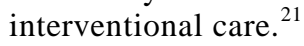

Moreover, elderly patients had more ICU rejections and higher mortality than younger population, although the benefit of ICU admission appeared greater for the elderly. ${ }^{22}$ Age alone cannot predict ICU outcomes; the severity of the acute illness was found more strongly associated with mortality. ${ }^{23}$

After the stabilization of acute problems, the elderly with good prognosis usually require prolonged rehabilitation, while those with poor prognosis need proper palliative care. One of the limitations in our geriatric ICU is admitting patients that require end of life care. The absence of appropriate hospice care service is one of the obstacles facing geriatric care model in Egypt.

This service was started in 2002 with only 8 ICU beds and 4 mechanical ventilators. The geriatric residents underwent 6 months of intensive care training in the medical critical care unit in Ain Shams University hospital. They also received the Fundamental Critical Care Support (FCCS) training.

In 2016, Intensive care was added as a mandatory curriculum for fulfillment of the Master Degree in Geriatrics provided by Ain Shams University.

\subsection{Geriatrics Intermediate care unit:}

It is considered a step down or step up medical unit between the geriatric medical ward and the Geriatric ICU for patients need close monitoring and medical support. This type of service was associated with earlier discharge, decreased mortality and proper allocation of ICU beds. ${ }^{24,25}$

This service was established in 2018 with highly equipped 12 beds providing the service for vulnerable frail elderly with medical emergency where the acute condition is stabilized and closely monitored to detect early deterioration of their condition allowing for rapid transferal to ICU when needed.

\subsection{Orthogeriatric care model (launched in 2018):}

It is the specialized geriatric medical care for older patients with orthopedic disorders. It is provided through the collaboration between Orthopedic, anesthesiology and Geriatric services.

The implementation of orthogeriatric model aims to reduce time to surgery, post-operative mortality, complications (delirium, DVT, Chest infection, deconditioning, polypharmacy), cost, and length of hospital stay.

\section{Services provided:}

- Preoperative assessment of elderly patients undergoing emergent or elective orthopedic surgeries.

- Fall prevention program.

- Osteoporosis detection and management service.

- Postoperative rehabilitation program

4.8. Home care:

Informal home care is provided as a freelancer service.

\section{Funding Resources for medical services:}

The medical expenses and operating costs are covered by Ain Shams University and the relevant governmental spending.

The new exclusive geriatric hospital-part of Ain Shams university hospitals-was primarily funded by a collaborative effort of an Egyptian philanthropist Mrs. Malak Khalil and "Misr el-kheir" which is one of the 
leading NGO in Egypt in addition to Ain Shams University and donations from the faculty staff.

\section{Number of patients:}

The outpatient clinics are serving about 25-30 patients daily, while the inpatient ward and ICU are serving 100 patients monthly.

Cutting-Edge Technology and innovative projects at Ain Shams University Geriatric hospital

\section{a) Promote adaptation of modern technology and expertise from other Centers of excellence.}

Project and outcome to date: This project involving adaptation of cutting-edge technology and expertise from outside Egypt to translate and adapt the innovative Brain Health Assessment (BHA) computerized cognitive screening test designed by the University of California San Francisco (UCSF) Memory and Aging Centre (MAC). ${ }^{26}$

Its adaptation is tied to an effort to make screening more widely available by negating the need of a specialist (geriatrician, psychiatrist, neurologist or neuropsychologist) and allowing non-specialists such as general practitioner and nurses to screen older adults in their homes or in community settings. BHA's ability to be administered by nurses, healthcare assistants or other health care allies allows for screening in the community setting. By approaching older adults in the places that are familiar to them i.e. community centers, places of worship, community events their willingness to be screened and their eventual participating in screening can be increased.

The Arabic translation and adaptation have been completed and the software is being prepared, the primary investigator used the modern standard Arabic language in order to be suitable for almost all native Arabic speakers (about 450 million). The Arabic version will be validated in Egyptian older adult population in collaboration with Ain Shams University hospital.

\section{b) Smart hospital: A part of falls prevention project}

Project and outcome to date: this project is tackling falls and related comorbidities as one of the most important geriatric giants.

There are several interventions for prevention and early detection of fall risk, ranging from the classical medical examination and comprehensive geriatric assessment which have very high sensitivity to detect risk of falls to modern technology and remote surveillance smart systems implemented in many nursing homes, dementia villages and elderly friendly hospitals in many countries.

A prototype of smart falls prevention protocol has been designed by a collaborative work between a team of researchers from Ain Shams Geriatric department and Megatronics department, Ain Shams faculty of engineering, composed of motion sensors, light sensors, pressure sensors in the patients' beds with wireless alarm system.

After completion of the current phase, a prospective study will be executed to measure the effectiveness and reliability of the project within the Egyptian community.

The responsible team succeeded to secure enough funding for the initial phase and working on the next steps of the project.

\section{c) Promote transfer of knowledge and expertise to outreach areas}

Despite the existence of geriatric medicine specialty in Egypt since 1990s, there is a massive shortage of geriatricians within the Egyptian community, with obvious discrepancy between the number of geriatricians and elderly population (Egypt is the second biggest populous country in Africa, counted 100 million with at least 7 million elderly above 60 years old). Not only the scarcity of number but also the widespread area of Egypt (about 1 million $\mathrm{Km}^{2}$ ) add a challenge to deliver the standard medical care i.e. assessment, investigation and treatment plan, from the geriatric medicine perspective. One of the smart ways to overcome this problem is the telemedicine and tele-mentoring platform that can remotely transfer knowledge and expertise from the central areas and university hospitals to outreach counties and governments.

Ain Shams geriatric department contributed to Ain Shams University Virtual hospital, which was founded one year ago as a collaborative work with the Neurology department,

Treat $\&$ Teach is an initiative launched by a group of Ain Shams university doctors and consultants with the aim of reducing the gap in the number of trained specialists as well as the deficiency of specialized training programs in Africa. Treat \& Teach also can help establish medical services in the benefiting institutions that would hopefully lead to nationwide services run by local resources to ensure sustainability. This can be achieved through the blended use of telemedicine and onsite training intertwined in a single program with clear targets. 


\section{d) electronic Geriatric Assessment Bundle "eGAB" as an Innovative software project.}

Comprehensive geriatric assessment (CGA) is not a widely used term outside of specialist circles despite being in existence for over 30 years.

CGA is a multidimensional, interdisciplinary diagnostic process to Identify care needs Plan care Improve outcomes of frail older people. The major purposes of CGA are to Improve diagnostic accuracy, optimize medical treatment, improve medical outcomes (including functional status and quality of life), optimize living location, minimize unnecessary service use and help to arrange long-term case management. ${ }^{27}$

Despite the huge beneficial impact of CGA, it is usually missed when dealing with elderly patients. Many barriers make CGA a challenging process like time consumption, lack of experience, diversity of geriatric medicine domains needed to be assessed, lack of awareness, global shortage of geriatricians....etc. so, a crucial necessity to simplify and figure out a solution for this problem.

eGAB is an android application incorporates selfadministered Arabic abbreviated and validated multidimensional assessment tools. It provides a systematic approach to detect subtle geriatric problems and identification of at-risk older persons in their homes. Instead of potentially not assessing a patient for functional, emotional, social, and cognitive limitations, this abbreviated selfadministered bundle would be an option for a quick screening tool to identify those who require further intensive evaluation with the full, multidisciplinary approach.

Egyptian Cognitive and Aging Research (ECARE) group finished the development of the e-GAB prototype as a user-friendly smartphone application and about to finish the validation process to be ready to use in wider range. $^{28}$

\section{e) Ain Shams Cognitive Training Lab}

This project started by training the first cohort of Egyptian specialists who will coordinate cognitive training classes and on creating the first international cognitive training lab in Egypt in collaboration with the

Greek Association of Alzheimer's Disease and Related Disorders (GAADRD).

This lab is designed to have a direct impact on the wider community. The main aim is to replicate the success of cognitive training programs in other nearby countries like Greece which have led to improvements in cognition, mood and quality of life for many older adults with cognitive problems.

Furthermore, it has had many psychosocial benefits for participants including social interaction, participation in other activities organized by the local Alzheimer's association and the sense of autonomy and accomplishment that comes with actively participating in maintaining and improving their brain health.

This project has had some impact in the Egyptian medical community as many brain health experts expressed interest in participating in the workshop with 20 of them participating and committing to promoting cognitive training.

The cognitive training lab is already founded at Ain Shams university geriatric hospital, and preparing a study to assess the cognition, mood and quality of life of the first cohort of older adults who will receive cognitive training, before and after the training intervention.

The cognitive training initiative is contributing to change of mindset of Egyptian society by training the first specialists who will promote cognitive training as an effective pathway to healthy aging to providing necessary practical information to caregivers across the whole region and reaching out to screen the brain health of older adults in community settings through innovative instruments, the focus is on reaching out directly to people in need of help and support and interacting with them in their own "terms".

\section{Training needed to ensure competence in the new model:}

\section{- Pregraduate training in geriatric medicine}

For one week included within the internal medicine curriculum. The training includes lectures, patient demonstrations and clinical attendance with a final exam.

The Physician Competencies of the American Geriatric Society (Minimum Geriatric Competencies for Medical Students) can be used as a guide ${ }^{29}$ available at:

https://www.americangeriatrics.org/sites/default/files/in line-files/Minimum-Geriatric-Competencies-MedicalStudents.pdf

\section{- Postgraduate training}

Trainees in Geriatric Medicine in a training program of five years duration.

- Academic programs:

The academic department was established in 1996, it is the first department in Egypt to issue academic degrees (Dip.,M.Sc., M.D) in geriatric medicine 


\section{Research in Geriatric Medicine}

The Department is active in research with multiple national and international publications. In 2014, the department founded of Ain Shams Ageing research center and The Egyptian journal of geriatrics and Gerontology

\section{Ways to go:}

We hope that in the near future, we can launch different levels of care e.g. palliative and hospice care, long-term care, and formal home care package programs and adding new specialized clinics to our hospital as incontinence, clinical nutrition clinics.

We hope that the progress of the Ain Shams university geriatrics model keeps pace with the global developments in elderly care.

Geriatricizing of the other healthcare disciplines is one of our main targets ${ }^{30}$ : we started by family physician in our university by incorporating a geriatric training Course within the postgraduate training. soon we may expand this concept to other discipline like internal medicine, neurology, cardiology.

\section{Strategic approaches for implementing a new geriatric care model:}

Five major strategic approaches can sum up the ASU$\mathrm{G} \& \mathrm{G}$ service development history. It is derived from the success and failure stories of development of elderly health care services in (Egypt: Ain Shams university, Alexandria university, Helwan university ...etc; Saudi Arabia: Imam Abdul Rahman bin Faisal university; among other international stories).

$1^{\text {st }}$ strategy: developing/preparing a fertile environment:

- Setting the scene (conference, media, courses ...etc)

- Raising awareness and promoting service

- Choosing wisely the academic or healthcare setting to plant the seed

- Networking with interested groups

- Find incubator department (mother/watcher/overseer)

- Start induction activities (courses, conf, sciseasons, lectures ...etc)

- Printed materials (Brochures, bulletans, journals)

- Scholarships intl \& regional

- Experts exchange visits

- Initiating NGOs and NGOs chapters

- Creating platforms (Conf, unit, scientific NGOs)

- Lobbying

- Governance $2^{\text {nd }}$ strategy: developing/preparing a home:

- Physical site office/room (dedicated, agefriendly architecture)

- Start administrative committee

- Keep umbilical cord with the mother for nurture till birth

- Secure financial resources flow e.g. NGOs \& GOs

- Good relations with neighbours and exchange visits at homes.

$3^{\text {rd }}$ strategy: developing/preparing inhabitants (service team):

- Start the Multidisciplinary team (MDT) (basic members \& complementary members)

$$
\text { o Regular MDT meetings }
$$

- Recruitment

o Fresh grads + induction courses

o Borrow staff from other departments

o Career shift for interested staff (Internal medicine, family medicine, neuropsychiatry ...etc)

- Skills

- All staff can work in a space station

o Core competencies (basic, essential, advanced)

o Change management

o Leadership

- Start a sustainable hatchery or production line of Geriatric HCP ASAP

o Residency program

o Postgrad studies: fellowships, Msc, MD

- $\mathrm{CPD} / \mathrm{CME}$ :

O Induction courses

o Journal club, clinical round, clinical cases, morning reports

o TOKA

- Know-how exchange:

o Scholarship intl \& regional

0 Expert exchange visits

- Localization and cloning of knowledge

o Think tank build up

o Centre of excellence

o Special interest groups

o TOKA

$4^{\text {th }}$ strategy: developing/preparing "ongoing service"

- MDT

- Management of change

- Criteria for admission, referral, discharge

- Key Performance Indicators \& audit

- Governance

- Review/revision meetings

- Intl \& regional experience stories reviews 


\section{$5^{\text {th }}$ strategy: developing preparing a center of excellence}

- Benchmarking

- Expansion, cloning

- Know how transferal to other regional centers

- Think tank

- TOKA

- $\mathrm{R} \& \mathrm{D}$

- Hatchery

- Publication products

\section{References:}

1- Tacitus, Agricola 27:1 (written 98AD)

2- WHO/FWC/ALC/17.1 - WHO 2017- (CC BY-NC-SA 3.0 IGO licence).

3- https://www.brainyquote.com/quotes/john_f_kennedy_110295.

4- UK 1983 JRSM

5- World report on ageing and health 2015.

6- Brummel NE, Ferrante LE. Integrating Geriatric Principles into Critical Care Medicine: The Time Is Now. Annals ATS. 2018 Jan 3;15(5):518-22.

7- World Population Ageing: 1950-2050, United Nations Population Division.

8- $\quad$ Chucks J. Population Ageing in Ghana: Research Gaps and the Way Forward. Journal of Aging Research 2010; 2010: 672157.

9- Issahaku PA and Neysmith S. Policy Implications of Population Ageing in West Africa. International Journal of Sociology and Social Policy 2013; 33 (3/4): 186-202.

10- https://www.indexmundi.com/Egypt Demographics Profile 2018. Accessed 26 March 2019

11- Rockwood K, Song X, MacKnight C, et al. A global clinical measure of fitness and frailty in elderly people. CMAJ. 2005;173(5):489-95. doi: 10.1503/cmaj.050051.

12- Rich Michael W., Chyun Deborah A., Skolnick Adam H., Alexander Karen P., Forman Daniel E., Kitzman Dalane W., et al. Knowledge Gaps in Cardiovascular Care of the Older Adult Population. Circulation. 2016 May 24:133(21):2103-22.

13- https://en.wikipedia.org/wiki/Geriatric_medicine_in_Egypt\#cite_ref14

14- Mohammedin AS. In memory of Abdel Moneim Ashour a forgotten pioneer of Geriatrics and Psycho geriatrics in Arab world. Egyptian Journal of Geriatrics and Gerontology. .2015; 2(1):1-9

15- Health care for the elderly : a comparative study between Egypt and the United States (1992): Erdman Ballagh Palmore and Abdel Moneim Ashour; Fulbright Commission in Egypt.; Ain Shams university Geriatrics Unit.; Egyptian A.Mohammedine.EJGG.2015; 2(1):1-9 Society for Geriatrics. - Publisher: [Cairo, Egypt?] : Fulbright Commission, O1992. - Series: Occasional paper series (Fulbright Commission in Egypt), v. 2, no. 1

16- Flaherty E, Hyer K, Fulmer T. Chapter 26. Team Care. In: Halter JB, Ouslander JG, Tinetti ME, Studenski S, High KP, Asthana S, editors. Hazzard's Geriatric Medicine and Gerontology, 6e [Internet]. New York, NY: The McGraw-Hill Companies; 2009 [cited 2019 Apr 6]. Available accessmedicine. mhmedical.com/content. aspx?aid $=5112834$

17- Flood KL, Allen KR. ACE units improve complex patient management. Todays Geriatr Med. 2013:6:28

18- The Statewide Older Person's Health Clinical Network. Level 6 Area Geriatric Service Acute Care of the Elderly Unit. Model of Care. October 2013

19- Department of Veterans Affairs. VHA HANDBOOK 1140.4

20- Nguyen HL, Saczynski JS, Gore JM, Goldberg RJ: Age and sex differences in duration of prehospital delay in patients with acute myocardial infarction: a systematic review. Circ Cardiovasc Qual Outcomes 2010:3:82-92.

21- Schoenenberger AW, Radovanovic D, Stauffer JC et al.: Age-related differences in the use of guideline-recommended medical and interventional therapies for acute coronary syndromes: a cohort study. J Am Geriatr Soc 2008;56:510-516.

22- Sprung $\mathrm{CL}$, Artigas A, Kesecioglu J et al.:The Eldicus prospective, observational study of triage decision making in European intensive care units. Part II: intensive care benefit for the elderly. Crit Care Med 2012; 40:132-8.

23- Brunner-Ziegler S, Heinze G, Ryffel M, Kompatscher M, Slany J, Valentin A."Oldest old" patients in intensive care: prognosis and therapeutic activity. Wien Klin Wochenschr 2007;119:14-9.

24- Prin M., Wunsch H. The Role of Stepdown Beds in Hospita Care. American Journal of Respiratory and Critical Care Medicine. 2014:190(11):1210-1216. doi: $10.1164 / \mathrm{rccm} .201406$ 1117PP.

25- Capuzzo M., Volta C. A., Tassinati T., et al. Hospital mortality of adults admitted to intensive care units in hospitals with and without intermediate care units: a multicentre European cohort study. Critical Care. 2014;18(5, article no. 18) doi: 10.1186/s13054014-0551-8.

26- Possin, K. L., Moskowitz, T. , Erlhoff, S. J., Rogers, K. M., Johnson, E. T., Steele, N. Z., Higgins, J. J., Stiver, J. , Alioto, A. G., Farias, S. T., Miller, B. L. and Rankin, K. P. (2018), The Brain Health Assessment for Detecting and Diagnosing Neurocognitive Disorders. J Am Geriatr Soc, 66: 150-156. doi:10.1111/igs.15208

27- Pilotto A, Cella A, Pilotto A, Daragjati J, Veronese N, Musacchio C, et al. Three Decades of Comprehensive Geriatric Assessment: Evidence Coming From Different Healthcare Settings and Specific Clinical Conditions. Journal of the American Medical Directors Association. 2017 Feb 1;18(2):192.e1-192.e11.

28- Rasheedy D. The New Paradigm of CGA. presented at The 6th International Ain Shams Geriatrics \& Gerontology Conference, Cairo, 2019

29- Leipzig R M, Granville L, Simpson D, Brownell Anderson M, Sauvigne K, and Soriano R P. (2009). Keeping granny safe on July 1: Consensus on minimum geriatric competencies for graduating medical students. Academic Medicine, 84, 604-610.

30- Williams B, Warshaw G, Walpole AM, Fabiny A, Schwartzberg JG, Lundjeberg $N$ et al. (2010). Medicine in the 21st century: Recommended essential geriatrics competencies for Internal Medicine and Family Medicine residents. Journal of Graduate Medical Education, 2(3), 373-383. Also available at http://www.jgme.org/doi/abs/10.4300/JGME-D-10-00065.1 
Appendix 1: Milestones and events of Geriatric medical service establishment in Egypt: (Ahmed Shawky Mohammedin)

Table 1: Time line of Milestones and events of ASU-G\&G service establishment

- 1980 Proposal for estab of ASU-G\&G administrative unit (special unit - Int med Neuropsy dpt) [Ashour]

- 1982 ASU-G\&G unit OPD start [A \& S]

- 1984 ASU-G\&G Daycare unit start [A \& O]

- 1990 IPD start

- 1991 Proposal to estab acad dpt [MS EGGS delegation] Fail

- 1994 Proposal to estab academic dpt [A] Success

- 1996 estab Academic dpt [A \& MM]

- 2001 Osteoporosis prevention \& TTT unit estab [A \& AKM]

- 2002 GICU unit estab [MM \& MSA]

- 2009 long term followup OPD estab [MSA]

- 2011 Ger 1ry care clinic estab [SH]

- 2018 Ger Hospital estab [SH \& HS]

- 2018 ASU-Orthogeriatric Model

- 2019 ASU- Memory Clinic

- 2019 ASU- Cognitive training lab

Table 2: Time line of Milestones and events of Egyptian Ger med service establishment

- 1980 Alex ger med unit [F]

- 1982 ASU-G\&G OPD start [A \& S]

- 1986 CU-G\&G unit trial

- 1996 Helwan dpt CEC [A \& KAH]

- 2006 Mansura [AS]

- 2009 Menufyia U

- 2014 SCU

- 2015 CU 2nd time

- 2016 Helwan univ

- 2016 Azhar univ

Table 3: Time line of Milestones and events of Egyptian elderly care governance (Healthcare \& social care)

- $\quad$ 1990s Nat elderly care committee (National Specialized councils)

- 1990 s Proposal for national elderly care institute ASU, CU,[A \& S] failed

- 1990s MOH - Geriatric medicine centers

- 2000s Ger med residencies-MOH

- 2011??? National council for elderly care [EH]

- 2012 Elderly care ministry proposal [A]

- 2019 BSU national elderly care institute [MSS] 
Table 4: Time line of Milestones and events of Egyptian Psyger services

- 1998 ASU-Research units

- 2008? Tanta univ Psyger

- 2015? CU-Psyger

- 2004 Abbasyia MH hosp Psyger unit [A]

- 2012 Psyger fellowship ASU [A]

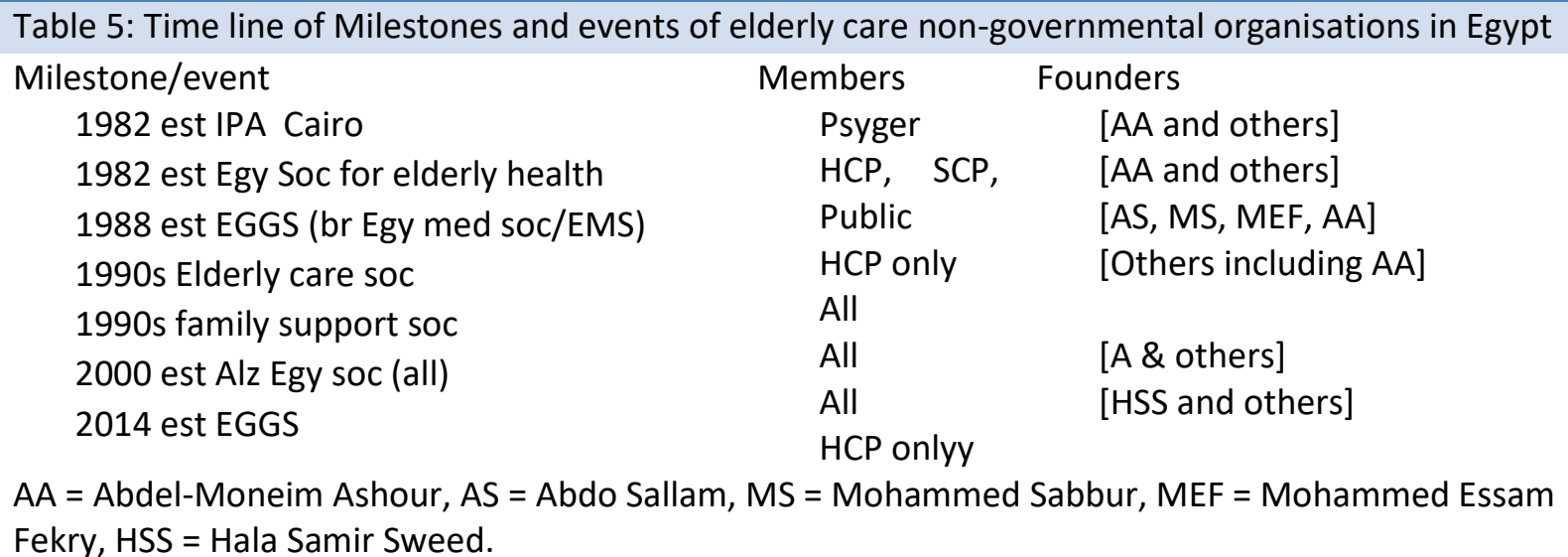

Fekry, HSS = Hala Samir Sweed.

Table 6: Time line of major professional networking events of Egyptian geriatrics healthcare services

- 1982 IPA conf Cairo (Psyger) [ASU \& IPA]

- 1989 1st G\& G conf (G \& G) [ASU]

- 1991 Induction courses at MOH hospitals \& health insurance (GM) [ASU, EGGS]

- 1994 2nd G \& G conference (G \& G) [EGGS]

- 1994- 1995-1996 -1997 Geriatric scientific seasons (G \& G) [ASU, Minessota univ, EGGS]

- AU-GMU conferences (2006-2010-2011-2014-2017-2018)

- ASU - G \& G dpt conferences (1989-1999-2014-2015-2016-2017-2018-2019)

- 2012 Middle East and North Africa Alzheimer disase conference [AA, Alz Egy]

- 1995 Sawt al-Zaman bulletin [MS, AA]

- 1999-present Alzheimer Egypt bulletin[AA, Alz Egy society]

- 2007 National elderly care strategy [EMRO, Team]

- 2014 The Egyptian journal of geriatrics \& gerontology [EGGS, ASU] 
Table 7: Time line of Milestones and events of elderly care building capacities in Egypt

\section{Milestone/event}

1977 Geriatrics Training scholarship at Birmingham university, UK

1970s Geriatrics scholarship at ....... UK

1978 Authoring the 1st geriatric medicine handbook

1980 Alex ger unit

1982 ASU ger unit

1986 CU ger unit (aborted)

1988 EGGS

1989 Proposal for Egyptian GM fellowship

1990s ASU-GMU \& UN-INIA collaboration

1991 GM physician competencies

1991 ASU Proposal to convert GMU to academic dpt

1991 AU Proposal to convert GMU to academic dpt

1992 ASU visiting professors exchange program with

Minnesotta university

1994 ASU Proposal for GM residency program, MSc \&

MD Post-graduate academic programs

1996 ASU academic GM dpt established plus GMU

1997 CEC, HU estab

1998 ASU Psyger research unit

2002 GICU

2006 Mansura university GMU

2007 National elderly care strategy

2012 ASU - Psyger fellowship

2013 SCU - GMU

$2015 \mathrm{CU}-\mathrm{GMU}$ ( $2^{\text {nd }}$ establishment)

2016 HU GMU

2016 ASU - GM fellowship

AA = Abdel-Moneim Ashour, AS = Abdo Sallam, MS = Mohammed Sabbur, MEF = Mohammed Essam Fekry, HSS = Hala Samir Sweed, MH = Maha Hosam, SH = Sara Hamza, MSA = Moatasem Salah Amer, MB = Mohammed alBAnouby, $\mathrm{KAH}=$ Khaled Abu-Hatab
Founders

[AA]

[MS]

[MS]

[MEF]

[AA]

[??]

[AS, MS, MEF, AA]

[MEF, EGGS]

[AA]

[MS]

[MS delegated by EGGS]

[MEF delegated by EGGS]

[AA, ASU, Fulbright foundation]

[[AA \& MS]

$[M S \& A A]$

[AA, KAH]

[AA \& others]

[MSA \& MB]

[AS]

[EMRO \& Team]

[AA, SAH]

[MH] 